\title{
How does the obesogenic environment impact on climate change?
}

\author{
M Holdsworth, B Maire and F Delpeuch \\ UMR NUTRIPASS, IRD-UM1-UM2-SupAgro, Montpellier, France
}

Introduction: Around 15\% of the global population is now obese or overweight and carbon emissions have increased from $250 \mathrm{ppm}$ (50 years ago) to $380 \mathrm{ppm}$ in 2007. Some have suggested that it is no coincidence that countries with higher obesity rates tend to have higher carbon emissions, such as the USA. This paper explores whether increasing obesity rates have an impact on climate change.

Method: A literature review of published research, including grey literature of the evidence for a link between obesity and climate change was conducted.

Results: Excess weight is caused by an imbalance between energy intake and energy expenditure. An increasing consumption of food, especially energy-dense processed foods, accompanied by a reduction in physical activity is involved in causing both obesity and climate change. The food chain makes a significant contribution to carbon emissions; contributing $\approx 1 / 5$ th of greenhouse gas emissions from food production, distribution and retailing; transport/travel and waste. Increased demand for energy-dense convenience food leads to increased $\mathrm{CO}_{2}$ emissions from processing, and carbon intensive packaging, as many prepared foods use oil-dependent plastic packaging. The rise in demand for convenience foods has contributed to a diet that is more energy dense, and therefore more obesity promoting. Reducing consumption of energy-dense foods back to European intakes of the 1990s would make enormous cuts in $\mathrm{CO}_{2}$ emissions. Convenience foods have often travelled many food miles. Increased consumption of energy-dense convenience foods then increases the risk of developing obesity. The key drivers in how a lack of physical activity contributes to climate change include increased car use, which lowers physical activity levels and increases carbon emissions. It is estimated that $\approx 40 \%$ of car journeys in the United Kingdom are $<3 \mathrm{~km}$, which could be walked in $<30 \mathrm{~min}$. Passenger cars now account for more than $13 \%$ of $\mathrm{CO}_{2}$ emissions in the United Kingdom and therefore make a significant contribution to global warming. It has been estimated that reverting back to walking patterns from the mid-1970s would result in a reversal of the obesity epidemic and a vast reduction in $\mathrm{CO}_{2}$ emissions. Redesigning the built environment to make it more favourable for walking and cycling, would be a solution to both obesity and climate change. Watching TV or using computers/gaming leads to increased $\mathrm{CO}_{2}$ emissions and is associated with weight gain.

Conclusions: Some of the policies widely evoked to tackle the obesogenic environment could also reduce greenhouse gas emissions. Examples include changes in urban design, making physical activity easier, benefiting both carbon emissions and BMI. Encouraging supermarkets and food manufacturers to demand reformulated products, shift marketing to healthier products and introduce food labelling will all help decrease obesity. Educating the public to change their attitudes in a more sustainable manner can be part of the solution, but alone it will not be enough. For further information: Globesity a planet out of control - Delpeuch, Maire, Holdsworth (2009). www.earthscan.co.uk:?tabid $=56997$

3rd Workshop - Communication - Keynote Speakers Communicating the messages of obesity prevention to the public

\author{
Richard Storey \\ Chief Strategy Officer M\&C Saatchi
}

Introduction: A cross-Governmental strategy Healthy Weight, Healthy Lives was initiated to combat the issue. Marketing was to form part of this strategy. The scale of the problem and its societal nature called for a new approach.
The Department of Health, working with M\&C Saatchi, developed a radical new social marketing strategy. Rather than a campaign, they used marketing to ignite a movement called Change4Life. Change4Life brings together 
individuals and organisations from across society to confront the growing issue of obesity. This movement promotes and supports the adoption of healthy behaviours through a vast array of channels and networks, helping people to change and to live a healthier lifestyle.

Method: In developing the campaign, the Department of Health in England was advised by leading academics working in nutrition, child psychology and physical activity, and undertook a major programme of quantitative, qualitative and ethnographic research. Armed with these insights and a detailed audience segmentation the Department worked with M\&C Saatchi to develop a communications strategy and create a brand with which to build a movement for change. The objective was to create a societal movement that would engage families, communities, grass roots organisations, teachers' healthcare professionals, NGOs and businesses, so that everyone could play their part in combating obesity. To create and then grow these movement some strategy principles were developed and deployed.

One: Make change positive. Rather than shouting at people Change4Life was created to be positive and supportive. This manifested itself in the name, colours and assets of the brand.
Two: Overcome the powerful rejection of obesity messages by reframing the problem as a societal one, rather than it being 'your fault'.

Three: Shifting the focus from 'fat bodies' to 'fat in the body' in order to avoid people excluding themselves and their families on physical grounds.

Four: Land the severity of the issue by revealing the true health harms caused by excess levels of body fat.

Five: Personalise the issue by finding levers that made the message relevant to people and their families.

Results: Over 400000 families have joined Change4Life. Change4Life has built over 200 national partnerships; $44 \%$ of community venues have displayed Change4Life materials; 26000 local supporters have held over a million conversations with the public about healthy lifestyles and National Health Service staff has ordered over six million items of Change4Life collateral. A third of all parents claim to have taken action as a direct result of Change4Life communications.

Conclusions: The programme has showed encouraging results in its first year. The team is working to underpin claimed data with proven measures of behaviour change, including an academic study and analysis of purchasing data from a major supermarket.

\title{
New instruments for communication: web, mobiles, sms, social networks
}

\author{
Jaqueline Harding
}

\section{Director of Tomorrow's Child and www.Parentchannel.tv}

The communication landscape is changing: Why do humans constantly desire new ways to communicate? Now that multi-modal texts are demanding that we rethink what it means to be literate it is important that we question how the reader/viewer's expectations have evolved and how new instruments for communication are being embraced. There is a growing demand for bite-sized information: it appears that, as consumers of communication, we are constantly seeking out faster methods of communication. Humans are distinct from other mammals. We are responsive to human interaction; biologically wired to connect with an altruistic drive to cooperate. Interestingly, it is recognised that socially connected people are less prone to stress. Perhaps there is a survival imperative that drives this demand for communication?

Traditional methods of communicating messages about nutrition and exercise are ceasing to work. Current discourse tends to concern access to information and new types of information. The rise of Internet TV is powerful: it is on the move; it is mobile; when you want it; where you want it; how you want it. So, how can new tools of communication help to present positive 'health' messages?

Addressing the target audience. Parents: Parents are children's first carers and promoters of their health. We sought to develop a more dynamic media-based approach to developing health awareness for both parent and child. Tomorrow's Child is founded on the North American Indian principle: no decision ever to be made without considering the needs of children seven generations hence. www. parentchannel.tv is a successful UK government initiative to bring key messages to parents of 5-19 years around: learning, well-being and behaviour. Tomorrow's Child is the production company who are providing short engaging and empowering films for this free online service. For example, films regarding:

How to get your children to enjoy eating healthy food; How to get a balanced diet on the table and Understanding and feeding your young vegetarian. Attracting the audience and effective methods of communication: Through online strategies such as, blogs, facebook, tweeting, vidtweets, youtube and most particularly through syndication methods, 